\title{
Análise do índice inicial de casos de Covid-19 relacionado aos indicadores sociais de saúde no estado do Pará, Brasil
}

\author{
Analysis of the initial index of cases of Covid-19 related to social health indicators in the \\ state of Pará, Brazil
}

Análisis del índice inicial de casos de Covid-19 relacionados con indicadores de salud social em el estado de Pará, Brasil

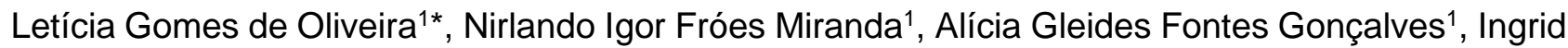
Tavares de Araújo ${ }^{1}$, Cássia Oliveira Cabral da Paz ${ }^{1}$, Brenda Stefany de Campos Chaves ${ }^{1}$, Marineuza Jardim Azevedo'.

\section{RESUMO}

Objetivo: Neste estudo o objetivo foi analisar o índice inicial de casos do novo Coronavírus da Síndrome Respiratória Aguda Grave 2 (SARS-CoV-2) no Pará (Brasil), e correlacionar com indicadores de saúde. Métodos: Trata-se de um estudo epidemiológico-descritivo dos casos confirmados e óbitos notificados pela Secretaria de Saúde do Estado do Pará. Resultados: Foram registrados 7054 casos sendo a maioria do sexo masculino $(52,3 \%)$ provenientes da capital do estado $(48,7 \%)$. Adultos jovens foram os mais acometidos pela infecção (22,5\%), contudo, o número de óbitos foi maior na faixa etária entre 60-69 anos (25,5\%), estando associado à comorbidades prevalentes como cardiopatias $(11,4 \%)$ e diabetes $(8,2 \%)$. Juntas essas condições aumentaram em massa a ocupação de leitos de UTI adulto $(86,6 \%)$ em todo estado. Conclusão: Nesse sentido, diante dos diferentes impactos sociais e de acesso a saúde exacerbados pela doença, é essencial reforçar a atuação conjunta de ações do governo e iniciativas individuais, visando a implementação de estratégias públicas que de fato sejam eficientes no controle desta pandemia.

Palavras-chave: Coronavírus, Pandemia, Epidemiologia.

\section{ABSTRACT}

Objective: In this study, the objective was to analyze the initial case index of the new Severe Acute Respiratory Syndrome Coronavirus 2 (SARS-CoV-2) in Pará (Brazil) and correlate it with health indicators. Methods: It is an epidemiological-descriptive study of confirmed cases and deaths notified by the State Health Department of Pará. Results: 7054 cases were registered, most of them male $(52.3 \%)$, with return on the state capital $(48.7 \%)$. Young adults were more affected by infection (22.5\%), however, the number of deaths washing her in the age group between $60-69$ years $(25.5 \%)$, associated with prevalent comorbidities such as heart disease $(11.4 \%)$ and diabetes (8.2\%). Together these conditions increased the occupation of adult ICU beds in bulk (86.6\%) statewide. Conclusion: In this sense, given the different social and access to health impacts exacerbated by the disease, it is essential to reinforce the joint action of government actions and individual initiatives, aiming at the implementation of public strategies that are in fact efficient in controlling this pandemic.

Keywords: Coronavirus, Pandemic, Epidemiology.

\section{RESUMEN}

Objetivo: En este estudio, el objetivo fue analizar el índice de caso inicial del nuevo Coronavirus Síndrome Respiratorio Agudo Severo 2 (SARS-CoV-2) en Pará (Brasil) y correlacionar lo con indicadores de salud. Métodos: Este es un estudio epidemiológico descriptivo de casos confirmados y muertes notificadas por el Departamento de Salud del Estado de Pará. Resultados: Se registraron 7054 casos, la mayoría hombres $(52,3 \%)$ provenientes de la capital del estado $(48,7 \%)$. Los adultos joven es fueron los más afectados por la infección (22.5\%), sin embargo, el número de muertes fue mayor en el grupo de edad entre 60-69 años

${ }^{1}$ Centro Universitário do Pará (CESUPA), Belém - PA. *E-mail: gomes_15_letici@hotmail.com SUBMETIDO EM: 5/2020 
(25.5\%), y se as oció con comorbilidades prevalentes como enfermedades del corazón (11.4\%) y diabetes $(8,2 \%)$. Juntas, estas condiciones aumentar on masivament el a ocupación de camas para adultos en la UCI $(86.6 \%)$ en todo el estado. Conclusión: En este sentido, en vista de los diferentes impactos sociales y el acceso a la salud exacerbado por la enfermedad, es esencial reforzar la acción conjunta de las acciones gubernamentales y las iniciativas individuales, con el objetivo de implementar estrategias públicas que de hecho se an efectivas para controlar esta pandemia.

Palabras clave: Coronavirus, Pandemia, Epidemiología.

\section{INTRODUÇÃO}

Os seres humanos sofreram dois surtos em larga escala de pneumonia causada por coronavírus nas duas primeiras décadas do século XXI, causada pelo coronavírus da síndrome respiratória aguda grave (SARSCoV) (DROSTEN C, et al., 2003) e coronavírus da síndrome respiratória no Oriente Médio (MERS-CoV) (ZAKI AM, et al., 2012). Em dezembro de 2019, 27 pacientes com infecção por pneumonia de etiologia desconhecida foram relatados na cidade de Wuhan, província de Hubei, China (HUANG C, et al., 2020). Mais tarde, em 7 de janeiro, um novo coronavírus denominado Coronavírus da Síndrome Respiratória Aguda Grave 2 (SARSCoV-2) foi identificado como o patógeno causador do COVID-19 (LU R, et al., 2020).

Os primeiros casos confirmados de COVID-19 foram especulados como tendo histórico de contato com um mercado de frutos do mar em Wuhan (ZHOU D, et al., 2020; ZHOU P, et al., 2020b). Logo, a transmissão de humano para humano foi revelada através da detecção de infecção em pelo menos um cluster doméstico (CHAN JFW, et al., 2020) e em profissionais de saúde que cuidam de pacientes com COVID-19 (WANG C, et al., 2020).

Enquantoa maioria das infecções por COVID-19 é assintomática ou mostra curso leve (CHINA, 2020; WU Z e MCGOOGAN JM, 2020), até 15\% dos pacientes desenvolvem uma doença respiratória grave e potencialmente fatal, com uma letalidade estimada entre 1,5 e mais de $10 \%$ (BAUD D, et al, 2020). Clinicamente, os sintomas comuns do COVID-19 geralmente cursam com febre, tosse, mialgia ou fadiga, hemoptise, diarreia, dispneia, linfopenia e insuficiência renal (CHEN N, et al., 2020). Mais recentemente, anosmia e outras formas de disfunção olfativa foram identificados em pacientes com COVID-19 (BAGHERI SHR, et al., 2020; BRANN D, et al., 2020).

A transmissão do SARS-CoV-2 entre humanos pode ocorrer por três vias (CHINA, 2020a): 1) transmissão direta por inalação de gotículas respiratórias (tosse ou espirro de pacientes infectados nas proximidades); 2) transmissão e contato através do toque de uma superfície ou objeto contaminado com o vírus (fômites); e 3) transmissão de aerossóis em espaços confinados. A via fecal-oral não parece efetiva, embora vírus viáveis tenham sido encontrados em fezes. Um estudo inicial sugere uma transmissibilidade ainda mais severa que a SARS-CoV (CASCELLA M, et al., 2020; DOREMALEN NV, et al, 2020; NASSIRI R, 2020; WHO, 2020).

Atualmente, como não há nenhum antiviral eficaz disponível, a letalidade parece depender dos fatores de risco individuais, incluindo padrão de resposta inflamatória, idade, sexo e hipertonia, e em caso de curso da doença para casos de pneumonia grave, da disponibilidade de unidades de terapia intensiva em grande escala (PEIRIS JSM, et al., 2003; ZHOU Y, et al., 2020).

O Protocolo de Manejo Clínico para o novo Coronavírus, elaborado pelo Ministério da Saúde, recomenda as seguintes medidas para prevenção: lavar com frequência as mãos com água e sabão até a altura dos punhos ou higienizar com álcool em gel 70\%; cobrir nariz e boca ao tossir ou espirrar com um lenço ou a região do antebraço; não levar a mão a face; evitar circulação desnecessária e qualquer contato físico; higienizar com frequência objetos de uso pessoal e evitar compartilhá-los; manter os ambientes limpos e bem ventilados; utilizar máscaras caseiras ou artesanais se precisar sair de casa (BRASIL, 2020a).

No Brasil, o primeiro caso foi registrado dia 17 de março de 2020 e de acordo com a última atualização do boletim epidemiológico (10 de maio de 2020) foram registrados 155.939 casos confirmados, com 10.627 óbitos (taxa de letalidade em 6,8\%), deste 16,4\% (25.565) dos casos foram, somente na região Norte (BRASIL, 2020b). 
No Pará, a primeira confirmação de COVID-19 ocorreu em 18 de março de 2020 e até 17 de maio de 2020 foram confirmados pela Secretaria de Saúde do Estado do Pará (SESPA) 13.464 casos e 1223 óbitos (PARÁ, 2020).

Diante do número expressivo de casos de COVID-19 e dos desafios para a saúde pública brasileira, tornase essencial preencher as lacunas de conhecimentos acerca da doença e sua epidemiologia, que permitam avaliar especificidades da população e a influência de fatores sociais nas taxas de transmissão do vírus, bem como a discussão acerca das medidas restritivas de circulação adotadas até o momento, que parecem ser de extrema importância sanitária. O objetivo deste estudo foi analisar o índice inicial de casos confirmados do novo coronavírus (SARS-Cov-2) no estado do Pará (Brasil) e correlacionar com indicadores sociais de saúde.

\section{MÉTODOS}

Trata-se de um estudo epidemiológico-descritivo dos casos confirmados e óbitos notificados de Covid-19 no estado do Pará, no período de 18 de março, que data o primeiro caso confirmado no estado, até 09 de maio de 2020.

O estado do Pará está situado na região norte, sendo o segundo maior estado do país em extensão territorial, com uma área de $1.247 .954 \mathrm{~km}^{2}$ e uma população de estimada em 8,6 milhões de habitantes, sendo em torno de 1,5 milhões na capital, Belém. Trata-se de um estado grande, porém marcado por aglomerações em centros urbanos e periferias, com extensas áreas rurais escassamente povoadas (IBGE, 2019a; IBGE, 2019b).

O estado é dividido em 6 mesorregiões (Baixo Amazonas, Marajó, Metropolitana de Belém, Nordeste Paraense, Sudoeste Paraense e Sudeste Paraense), 143 municípios, onde nenhum deles possui índice de desenvolvimento humano (IDH) "Muito Alto", sendo a maioria classificado com IDH "Médio" e "Baixo". O estado é classificado como terceiro estado com menor renda per capita do país (em média $R \$ 807$ ou USD 137,00 em valores convertidos) e tem o pior desempenho entre os estados do Norte. Além disto, o estado é um dos líderes no país em trabalhos informais. Dados do IBGE apontam que o Pará é o segundo no Brasil em números de pessoas trabalhando por conta própria (IBGE, 2019d; IPEA, 2016).

Foram incluídos na pesquisa todos os casos confirmados de Covid-19 em residentes do estado divulgados pela SESPA. A evolução dos casos foi monitorada através das macrorregiões de saúde e para isto foram extraídos dados dos boletins epidemiológicos disponibilizados pela SESPA, onde constam todos os casos confirmados e óbitos no período de estudo.

As variáveis analisadas foram: sexo, faixa etária, procedência, comorbidades e taxa de ocupação dos leitos no estado do Pará. Os dados foram organizados, tabulados e analisados por meio do software Microsoft Office Excel 2013®, no qual foram aplicadas análises estatísticas descritivas e a produção de tabelas e gráficos. Para análise espacial os dados foram alocados por figuras temáticas com o auxílio do programa Metabase@ 2020. Os mapas foram obtidos junto a SESPA.

A pesquisa dispensou avaliação do Comitê de Ética em Pesquisa, por tratar-se de dados epidemiológicos de um banco de domínio público, estando de acordo com a resolução o 510 de 07 de abril de 2016 do Conselho Nacional de Saúde que disciplina pesquisas realizadas com seres humanos e nos termos da Lei $n$ o 12.527 de 18 de novembro de 2011 que regulamenta as pesquisas que utilizem informações de acesso público (BRASIL, 2016; BRASIL, 2011).

\section{RESULTADOS}

Foram investigados todos os casos que confirmados entre 18/03/2020 a 09/05/2020, durante esse período a SESPA registrou 7054 casos. Como demonstrado no Gráfico 1 houve crescimento significativo da ocorrência de casos, sendo dia 06/05/2020 a data recorde de confirmação diária, com 768 registros.

Nota-se no Gráfico 1 que o pico de transmissão se deu a partir do dia 05 de abril de 2020, provavelmente devido ao início de ocorrências de transmissão comunitária, assim os portadores não souberam identificar como e de quem adquiriram o vírus. 
Gráfico 1 - Evolução diária de casos confirmados de COVID-19 no Estado do Pará, Brasil.

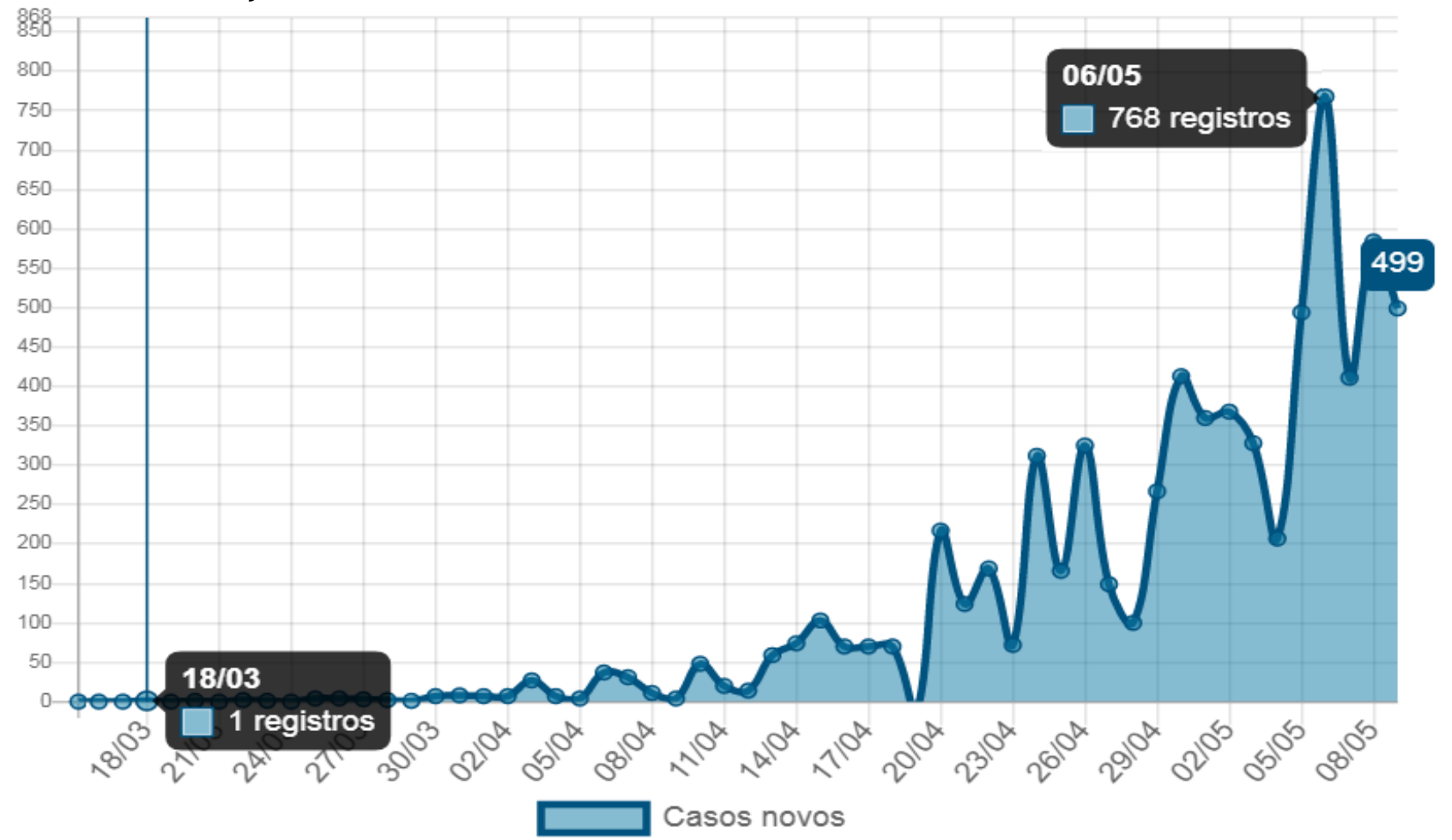

Fonte: Oliveira LG, et al., 2020. Dados coletados pela Secretaria de Saúde do Estado do Pará (SESPA), 2020.

Foram analisados 7054 casos, onde 52,3\% (3689/7054) eram do sexo masculino. Na população examinada a maior frequência estava na faixa etária de 30 a 39 anos, o que correspondeu a $22,5 \%$ (1585/7054) e a menor frequência foi encontrada entre os menores de nove anos de idade em $1,4 \%$ (104/7054). A Tabela 1 ilustra ainda que 0,5\% (30/7054) foram ignorados, ou seja, encontraram-se sem essas informações.

Tabela 1 - Distribuição de casos confirmados de COVID-19 por faixa etária e sexo, estado do Pará Brasil.

\begin{tabular}{|c|c|c|c|c|c|c|}
\hline \multirow{2}{*}{$\begin{array}{c}\text { Faixa etária } \\
\text { (anos) }\end{array}$} & \multicolumn{2}{|c|}{ População } & \multicolumn{4}{|c|}{ Sexo } \\
\hline & Examinada & $\%$ & Masculino & $\%$ & Feminino & $\%$ \\
\hline 0 a 9 & 104 & 1,4 & 64 & 61,5 & 40 & 38,5 \\
\hline 10 a 19 & 105 & 1,5 & 54 & 51,4 & 51 & 48,6 \\
\hline 20 a 29 & 868 & 12,3 & 384 & 44,2 & 484 & 55,8 \\
\hline 30 a 39 & 1585 & 22,5 & 775 & 48,9 & 810 & 51,1 \\
\hline 40 a 49 & 1528 & 21,7 & 800 & 52,3 & 728 & 47,6 \\
\hline 50 a 59 & 1077 & 15,2 & 588 & 54,6 & 489 & 45,4 \\
\hline 60 a 69 & 867 & 12,3 & 518 & 59,6 & 349 & 40,4 \\
\hline 70 a 79 & 539 & 7,6 & 308 & 57,1 & 231 & 42,9 \\
\hline$>80$ anos & 351 & 5,0 & 186 & 53,0 & 165 & 47,0 \\
\hline Ignorado & 30 & 0,5 & 18 & 60,0 & 12 & 40,0 \\
\hline Total & 7054 & 100,0 & 3689 & 52,3 & 3365 & 47,7 \\
\hline
\end{tabular}

Fonte: Oliveira LG, et al., 2020. Dados coletados pela Secretaria de Saúde do Estado do Pará (SESPA), 2020. 
Quanto ao número de óbitos por COVID-19, foram registrados 610 no período analisado do estudo, onde $62,6 \%$ eram do sexo masculino. Na população examinada a maior frequência de óbitos estava na faixa etária de 60 a 69 anos, em $25,5 \%$ (156/610) e a menor frequência foi encontrada entre os menores de nove anos em $0,3 \%$ (2/610), conforme a Tabela 2.

Tabela 2 - Distribuição de óbitos por covid-19 de acordo com a faixa etária e sexo, Pará, Brasil.

Faixa etária População Sexo

\begin{tabular}{|c|c|c|c|c|c|c|}
\hline (anos) & Examinada & $\%$ & Masculino & $\%$ & Feminino & $\%$ \\
\hline 0 a 9 & 2 & 0,3 & 2 & 100,0 & - & - \\
\hline 10 a 19 & 4 & 0,6 & 1 & 25,0 & 3 & 75,0 \\
\hline 20 a 29 & 12 & 2,0 & 6 & 50,0 & 6 & 50,0 \\
\hline 30 a 39 & 25 & 4,1 & 17 & 68,0 & 8 & 32 \\
\hline 40 a 49 & 59 & 9,7 & 44 & 74,6 & 15 & 25,4 \\
\hline 50 a 59 & 85 & 14,0 & 62 & 72,9 & 23 & 27,1 \\
\hline 60 a 69 & 156 & 25,5 & 100 & 64,1 & 56 & 35,9 \\
\hline 70 a 79 & 137 & 22,5 & 80 & 58,4 & 57 & 41,6 \\
\hline$>80$ anos & 130 & 21,3 & 70 & 53,8 & 60 & 46,2 \\
\hline Total & 610 & 100,0 & 382 & 62,6 & 228 & 37,4 \\
\hline
\end{tabular}

Fonte: Oliveira LG, et al., 2020. Dados coletados pela Secretaria de Saúde do Estado do Pará (SESPA), 2020.

O estado do Pará possui 144 municípios, dos quais 130 já possuem ao menos um caso de COVID-19 registrados. Belém é a capital e sua maior cidade com 1,5milhõesde habitantes em 2019 e Ananindeua, com 530,5 mil habitantes (IBGE, 2019b; IBGE, 2019c). Belém é o município com maior número de casos confirmados (3441), óbitos (317) e letalidade em 9,21\%, seguido do município vizinho Ananindeua, conforme ilustra a Tabela 3.

A Figura 1 reforça os dados da Tabela 3, mostrando o mapa de calor dos casos confirmados agrupados por município, onde identifica a capital Belém e os municípios ao redor sendo áreas mais intensas e de maior frequência dos casos. Cabe ressaltar, que este mapa leva em consideração os casos acumulados agrupados por município e não cada caso isoladamente. 
Tabela 3 - Distribuição dos casos confirmados, óbitos e letalidade do covid-19 por município no estado do Pará.

Município Confirmados Óbitos Letalidade

\begin{tabular}{|c|c|c|c|}
\hline Belém & 3441 & 317 & $9,21 \%$ \\
\hline Ananindeua & 705 & 46 & $6,52 \%$ \\
\hline Castanhal & 196 & 21 & $10,71 \%$ \\
\hline Breves & 187 & 29 & $15,51 \%$ \\
\hline Cametá & 148 & 12 & $8,11 \%$ \\
\hline Parauapebas & 132 & 21 & $15,91 \%$ \\
\hline Santarém & 126 & 14 & $11,11 \%$ \\
\hline Bragança & 109 & 10 & $9,17 \%$ \\
\hline Santa Izabel do Pará & 97 & 2 & $2,06 \%$ \\
\hline Marabá & 95 & 22 & $23,16 \%$ \\
\hline Santo Antônio do Tauá & 87 & 7 & $8,05 \%$ \\
\hline Marituba & 73 & 4 & $5,48 \%$ \\
\hline Capanema & 72 & 6 & $8,33 \%$ \\
\hline Abaetetuba & 67 & 11 & $1,49 \%$ \\
\hline Benevides & 59 & 7 & $11,86 \%$ \\
\hline Vigia & 59 & 3 & $5,08 \%$ \\
\hline São Miguel do Guamá & 58 & 2 & $3,45 \%$ \\
\hline Paragominas & 56 & 3 & $5,36 \%$ \\
\hline Barcarena & 46 & 5 & $10,87 \%$ \\
\hline Tailândia & 45 & 00 & $0 \%$ \\
\hline Salinópolis & 42 & 3 & $7,14 \%$ \\
\hline Altamira & 39 & 11 & $2,56 \%$ \\
\hline Ponta de Pedras & 37 & 3 & $8,11 \%$ \\
\hline Bujaru & 34 & 3 & $8,82 \%$ \\
\hline Concórdia do Pará & 34 & 0 & $0 \%$ \\
\hline Igarapé-Miri & 31 & 2 & $6,45 \%$ \\
\hline Curuçá & 28 & 3 & $10,71 \%$ \\
\hline Maracanã & 28 & 11 & $3,57 \%$ \\
\hline São Caetano de Odivelas & 28 & 5 & $17,86 \%$ \\
\hline Igarapé-Açu & 25 & 4 & $16 \%$ \\
\hline Augusto Corrêa & 24 & 2 & $8,33 \%$ \\
\hline Tucuruí & 23 & 6 & $26,09 \%$ \\
\hline Conceição do Araguaia & 22 & - & $0 \%$ \\
\hline Mãe do Rio & 22 & - & $0 \%$ \\
\hline Ipixuna do Pará & 21 & - & $0 \%$ \\
\hline Oeiras do Pará & 20 & 11 & $5 \%$ \\
\hline Santa Bárbara do Pará & 20 & 11 & $5 \%$ \\
\hline Demais Municípios & $<20$ cada & $\leq 11$ & $0-20 \%$ \\
\hline
\end{tabular}

Fonte: Oliveira LG, et al., 2020. Dados coletados pela Secretaria de Saúde do Estado do Pará (SESPA), 2020. 
Figura 1 - Mapa de calor dos casos confirmados agrupados por município do estado do Pará, Brasil.

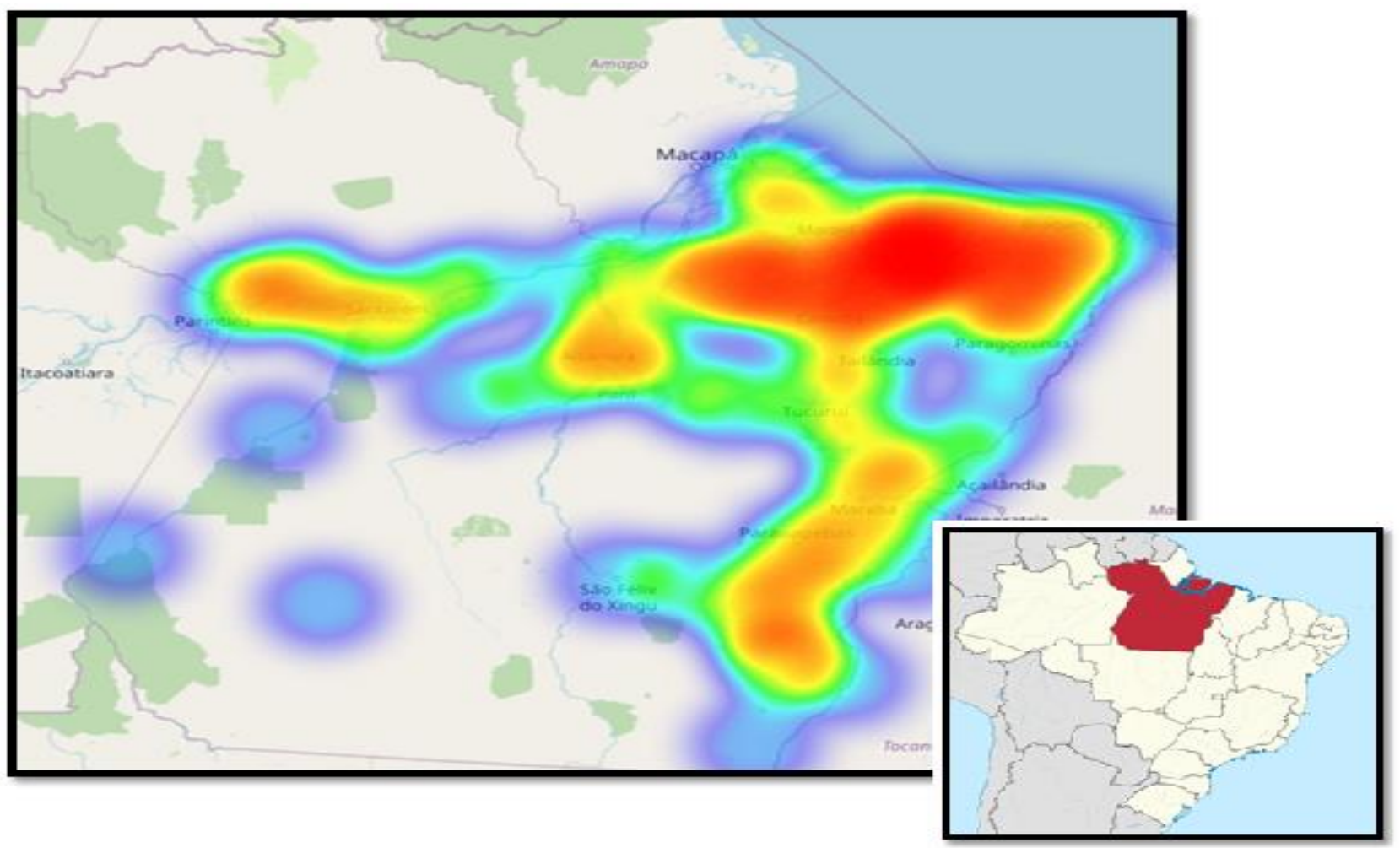

Fonte: Oliveira LG, et al., 2020. Dados coletados pela Secretaria de Saúde do Estado do Pará (SESPA), 2020.

Em relação às comorbidades associadas aos diagnósticos de Covid-19, houve maior ocorrência de cardiopatias $(11,4 \%)$, seguido de diabetes $(8,2 \%)$. As de menores frequências encontradas estavam às neuropatias, hepatopatias e hematopatias com menos de 0,5\% cada, conforme ilustra o Gráfico 2 a seguir.

Gráfico 2 - Perfil de comorbidades associados aos casos de Covid-19 no estado do Pará, Brasil.

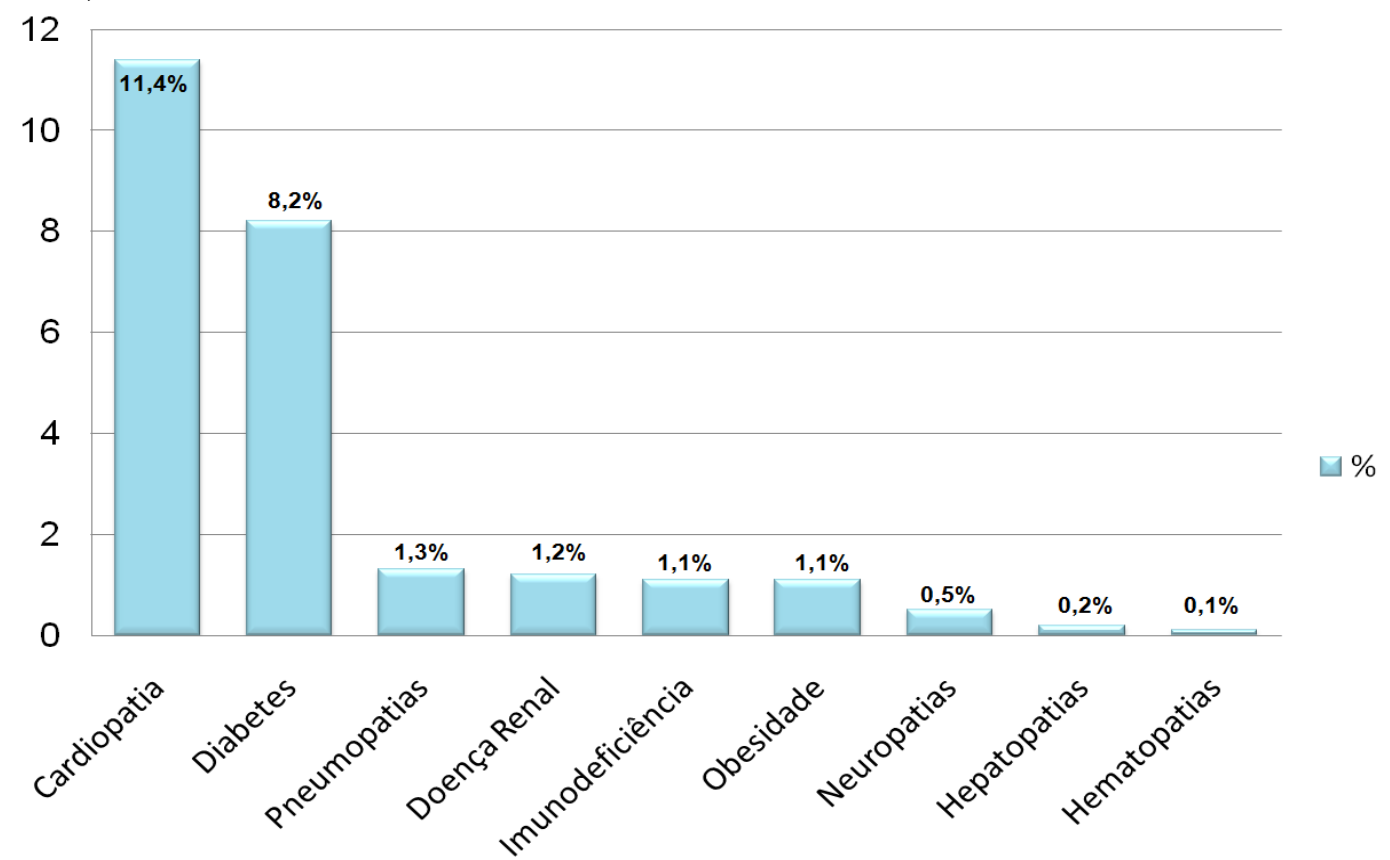

Fonte: Oliveira LG, et al., 2020. Dados coletados pela Secretaria de Saúde do Estado do Pará (SESPA), 2020. 
Quanto aos leitos exclusivos para os casos de Covid-19 sobre gestão do governo do estado do Pará, as Unidades de terapia Intensiva adulto (UTI adulto) está com 82,6\% dos seus leitos ocupados, seguido das Unidades de terapia Intensiva Neonatal com $75 \%$ de ocupação. As unidades intermediárias e clinico pediátrico estão totalmente (100\%) disponivel, conforme a Tabela 4.

Tabela 4 - Distribuição dos tipos leitos exclusivos para os casos de Covid-19 por disponibilidade e taxa de ocupação, sobre gestão do governos do estado do Pará, Brasil.

\begin{tabular}{lccc}
\hline \multicolumn{1}{c}{ Tipo de leitos } & Total & Disponível & Taxa de ocupação (\%) \\
\hline UTI Adulto & 259 & 45 & $82,6 \%$ \\
UTI Neonatal & 4 & 1 & $75 \%$ \\
Clínico & 1109 & 516 & $53,5 \%$ \\
UTI Pediátrica & 7 & 4 & $42,8 \%$ \\
Unidade Intermediária & 26 & 26 & $0 \%$ \\
Clínico pediátrico & 8 & 8 & $0 \%$
\end{tabular}

Fonte: Oliveira LG, et al., 2020. Dados coletados pela Secretaria de Saúde do Estado do Pará (SESPA), 2020.

Era possível ver nos noticiários que o estado do Pará se encontrava em situação gravíssima, principalmente devido à falência da porta de entrada ao sistema de saúde, o que pode ter resultado no agravamento de quadros em situações passíveis de reversão sem necessidade de cuidados intensivos, dessa forma, sobrecarregando os leitos de UTIs disponíveis na rede.

Acredita-se que as unidades básicas de saúde, frequentemente marcadas por carência de recursos humanos, materiais e de estrutura, além de obstáculos administrativos e assistenciais, poderiam ter minimizado o quadro se implementassem precocemente iniciativas descentralizadas de educação em saúde em seus respectivos bairros, em especial, na região Metropolitana de Belém.

\section{DISCUSSÃO}

A sobrecarga do sistema de saúde pública previsto em países em desenvolvimento e, inclusive, em países ricos e com melhor estrutura de redes de saúde, foi inevitável na capital paraense (ARMOCIDA B, et al., 2020).

Esse cenário é preocupante, visto que se traduz no aumento da mortalidade nas localidades onde os serviços de saúde não estão aptos para acompanhar o acréscimo da demanda. Ao tratar-se da região Norte e Nordeste, Noronha KVMS, et al. (2020), ressaltam a grande fragilidade da oferta de serviços na área da saúde nessas regiões, sendo agravada principalmente pelos vazios assistenciais e pela propagação acelerada da doença.

A taxa de incidência no estado, que considera a quantidade de casos registrados para cada 100 mil habitantes, até a $8^{\text {a }}$ semana desde o primeiro caso confirmado foi de foi de aproximadamente 87,3 (SESPA, 2020). O número de óbitos se comportou da mesma forma em relação ao restante do planeta, tendo uma letalidade de aproximadamente $8,64 \%$, ou 7,5 para cada 100 mil habitantes, em relação à paises que encontram-se mais a frente na dinâmica da pandemia, está acima da China $(3,8 \%)$ e semelhante a Itália $(9 \%)$ (CHINA, 2020; ITÁLIA, 2020).

É importante salientar que, desde o início da pandemia até o atual momento, disparidades se tornaram evidentes nos dados de diferentes países. Isso pode estar relacionado ao fato de os países adotarem diferentes medidas de enfrentamento ao vírus, como por exemplo, adoção ou não de testes diagnósticos em massa disponíveis para a população. 
Além deste, dentre outros pontos mencionados na literatura, pode-se citar: a iniciativa governamental para a proibição de reuniões com determinada quantidade de pessoas, o fechamento de cinemas, de shopping, assim como o fechamento de escolas entre outros. Quando tais condutas são combinadas com as medidas de isolamento de casos e à quarentena de contatos, o resultado pode ser mais efetivo no combate a pandemia (AQUINO EML et al., 2020).

Nota-se que há uma grande discrepância na porcentagem de óbitos na capital em relação aos interiores do estado, sendo possível visualizar na Tabela 3 que frequentemente os municípios mai afastados da capital apresentam taxa de letalidade acima de $10 \%$ sendo, em alguns casos, possível visualizar até mesmo municípios que registram acima de $20 \%$ de letalidade (SESPA, 2020). Este fato pode estar relacionado condições insatisfatórias dos serviços de saúde nesses municípios, que geralmente apresentam menor disponibilidade de leitos de terapia intensiva para a população.

A incapacidade dos governos de minimizar totalmente as mortes pela doença e o impacto econômico da propagação viral já era esperada por alguns cientisticas. Por isso, manter a menor mortalidade possível seria a maior prioridade para os indivíduos e governos (ANDERSON RM, et al., 2020).

Dessa forma, o mais recomendável seria adotar medidas que possam promover o achatamento da curva epidêmica, impedindo assim o aumento abrupto e exponencial dos números de casos para então minimizar as demandas que recaem em cima dos serviços de saúde, os quais já erm saturados no período prépandemia; e com isso evitar o aumento da taxa de óbitos, gerando um fluxo mais fluido no sistema de saúde e assistência com melhor qualidade (NORONHA KVMS, et al., (2020)

O mapa de calor apresentado na Figura 1 demonstra um cenário já esperado: o epicentro do estado sendo na região Metropolitana de Belém, onde concentra aproxidamente $30 \%$ da população de todo estado $(2,5$ milhões de habitantes) reunida em apenas 7 municípios. É importante salientar que o número de casos no interior ainda está reduzido e a tendência de acordo com a dinâmica da pandemia em demais estados, o vírus avance para os interiores, suprimindo ainda mais o sistema de saúde nessas áreas podendo, inclusive, forçar estes pacientes a buscarem por assistência na capital do estado ou aos serviços a transferirem seus pacientes (SESPA, 2020).

O Gráfico 2 demonstra uma um cenário preocupante, onde pelo menos $20 \%$ das pessoas diagnosticadas apresentam no mínimo uma comorbidade, o que pode estar relacionada a alta mortalidade encontrada em alguns minicípios. A evidência para associação da COVID-19 com morbidade e mortalidade está crescendo em doenças cardiovasculares, principalmente. O SARS-CoV 2 liga-se ao receptor da enzima conversora de angiotensina 2 (ECA2) humana após ativação da proteína transmembranar serina 2 (TMPRSS2) (HOFFMAN M, et. al., 2020; ZHAO Y, et al., 2020).

A ECA2 é principalmente expressa nos pulmões, que parece ser o local de acesso dominante. A ECA2 é altamente liberada no coração em casos de ativação do sistema renina-angiotensina, como em hipertensão arterial sistêmica, insuficiência cardíaca congestiva e aterosclerose. Além dos seus efeitos cardíacos, a ECA2 é expressa nos pulmões, epitélio intestinal, endotélio vascular e rins, sendo uma das causas principais de falência de múltiplos órgaos em infecção pelo SARS-CoV-2 (HOFFMAN M, et. al., 2020; ZHAO Y, et al., 2020; TIKELLIS C e THOMAS MC, 2020; ZHANG H, et. al., 2020).

A Tabela 4, que demonstra a distribuição dos tipos leitos exclusivos para os casos de COVID-19 por disponibilidade e taxa de ocupação, sob gestão do governos do estado, mostrava um cenário já preocupante, onde a taxa de ocupação de leitos de UTI adulto e pediátricas atingiram $82,6 \%$ e $75 \%$, respectivamente. Vale ressaltar, que os dados coletados datam aproximadamente uma semana antes do pico de contágio, que estaria previsto para ocorrer entre 12 e 14 de maio, portanto, torna-se essencial minimizar a morbidade e mortalidade associada, a fim de evitar um pico epidêmico que sobrecarregue os serviços de saúde.

Levando em consideração que pacientes com COVID-19 que necessitem de suporte de ventilação mecânica, consequentemente, de leitos de UTI, levam aproximadamente 14 dias para terem alta da terapia intensiva, podemos concluir que a saturação destes leitos tem chances consideráveis de ocorrer (AMIB, 2020). A abordagem adotada pelas autoridades, de fechamento total de serviços não-essenciais, estratégia de lockdown, que está em andamento no estado fornecerá dados valiosos acerca da eficácia de tais medidas. 
Reformaçamos que a ação de iniciativa pessoal pode ser uma atitude importante para a eficácia das medidas adotadas pelo governo, requerendo com menos frequência serviços essenciais como idas a farmácias, feiras e supermercados; suspender completamente a visita a familiares e pessoas que não residam em sua residência; adoção de aconselhamento médico remoto e buscar assistência médicaapenas em momentos que os sintomas se tornem importantes.

O principal questionamento é sobre como ser possível que o modo e as condições de vida da população não interfiram no impacto das estratégias para mitigação da taxa de infecção? Como visto anteriormente, o estado do qual se trata este estudo é populoso, possui um baixo índice de desenvolvimento humano e social,é pobree, principalmente, possui uma parcela da população tendo o mercado informal como sua principal fonte de renda (IBGE, 2019; IPEA, 2019)

Isto pode contribuir fortemente para que medidas de prevenção não sejam plenamente praticadas, bem como as medidas de distanciamento social, visto que a maioria desta população pode sofrer com mais gargalos logísticos e financeiros que podem vir a dificultar o acesso a assistência em saúde de forma remota, como também criar obstáculos para reduzir idas a supermercados, feiras e afins.

Além disso, a dependência do trabalho para o sustento diário pode gerar hesitação para adotar medidas de distanciamento social, visto que medidas para reduzir o risco de infecção e medidas para manter a situação econômica em níveis razoáveis cursam em direções opostas.

Ressalta-se que o presente estudo apresentou algumas limitações, dentre estas a existencia de dados incompletos e a constante atualização da plataforma de armazenamento destes dados. Sabe-se também que mesmo diante aos esforços e necessidade de notificação, existe um considerado numero de casos subnotificados, principalmente pela ausencia de ampla testagem para diagnóstico.

Contudo, os achados epidemilógicos encontrados são de granderelevância científica, e portanto fundamentaispara a identificação dos fatores clinico-epidemiológicos relacionados a doença, sua progressão, bem como para otimizar aimplementação de estratégias públicas de intervenção que sejam eficientes ao controle desta pandemia.

\section{CONCLUSÃO}

Mediante ao exposto, os indivíduos do sexo masculino, adultos jovens, com pelo menos uma comorbidade, foram mais frequentes entre os infectados e, apesar da região metropolitana de Belém deter a maior parte dos casos, os municípios interioranos possuem maior taxa de letalidade, e mesmo com adoção de estrategias por parte das autoridades governamentais para o enfrentamento do COVID-19, os dados epidemiológicos referentes ao Pará são alarmantes, expondo a dificuldade de articulação e capacidade de oferta dos serviços de saúde em proporção a demanda incrementada.

\section{REFERÊNCIAS}

1. AMIB. Associação de Medicina Intensiva Brasileira. Comunicado da AMIB sobre o avanço do COVID-19 e a necessidade de leitos de UTIs no futuro. 2020.

2. ANDERSON RM, et al. How will country-based mitigation measures influence the course of the COVID-19 epidemic?The Lancet, 2020; 395: 931-34.

3. AQUINO EML, et al. Medidas de distanciamento social no controle da pandemia de COVID-19: potenciais impactos e desafios no Brasil. Ciênc. saúde coletiva, 2020; 25: 2423-2446.

4. ARMOCIDA B, et al. The Italian health system and the COVID-19 challenge. The Lancet, 2020; 5: e232.

5. BAGHERI SHR, et al. Coincidence of COVID-19 epidemic and olfactory dysfunction outbreak. Otolaryngology, 2020.

6. BAUD D, et al. Real estimates of mortality following COVID-19 infection. The Lancet Infect Dis. 2020.

7. BRANN D, et al. 2020. Non-neural expression of SARS-CoV-2 entry genes in the olfactory epithelium suggests mechanisms underlying anosmia in COVID-19 patients (preprint). Neuroscience, 2020.

8. BRASIL. Ementa Constitucional № 12.527, de 18 de janeiro de 2011. Lei №12.527, de 18 de novembro de 2011. 2011.

9. BRASIL. Ministério da Saúde. Diário Oficial da União. RESOLUÇÃO № 510, DE 7 DE ABRIL DE 2016. 2016.

10. BRASIL. Ministério da Saúde. Secretaria de Atenção Especializada em Saúde. Protocolo de Manejo Clínico para o Novo Coronavirus, Brasília, 2020a; 4(1): 7-16. 
11. BRASIL. Ministério da Saúde. Secretaria de Vigilância em Saúde. Painel de casos de doença pelo coronavírus 2019 (COVID-19) no Brasil pelo Ministério da Saúde. 2020b.

12. CASCELLA M, et al. Features, Evaluation and Treatment Coronavirus (COVID-19). [Atualizadoem 8 março 2020] In: StatPearls [Internet]. Treasure Island (FL): StatPearls Publishing; 2020.

13. CHAN JFW, et al. A familial cluster of pneumonia associated with the 2019 novel coronavirus indicating persontoperson transmission: a study of a family cluster. The Lancet, 2020, 395, 514-523.

14. CHEN N, et al. Epidemiological and clinical characteristics of 99 cases of 2019 novel coronavirus pneumonia in Wuhan, China: a descriptive study. The Lancet 2020, 395, 507-513.

15. CHINA. Epidemiology Working Group for NCIP Epidemic Response, Chinese Center for Disease Control and Prevention. The epidemiological characteristics of an outbreak of 2019 novel coronavirus diseases (COVID-19) in China. Zhonghua Liu Xing Bing XueZaZhi, 2020; 41(2): 145-151.

16. CHINA. National Health Commission. Pneumonia diagnosis and treatment of 2019-nCoV infection from Chinese NHC and CDC 2020. 2020a.

17. DOREMALEN NV, et al. [Correspondece]. Aerosol and Surface Stability of SARS-CoV-2 as Compared with SARSCoV-1. Destinatário: The New England Journal of Medicine. Massachusetts, 2020.

18. DROSTEN C, et al. Identification of a novel coronavirus in patients with severe acute respiratory syndrome. N. Engl. J. Med. 2003; 348: 1967-1976.

19. HOFFMANN M, et al. SARS-CoV-2 cell entry depends on ECA2 and TMPRSS2 and is blocked by a clinically proven protease inhibitor. Cell. 2020; 181(2):271-80.

20. HUANG C, et al. Clinical features of patients infected with 2019 novel coronavirus in Wuhan, China. The Lancet, 2020. 395, 497-506.

21. IBGE. Instituto Brasileiro de Geografia e Estatística. Pará. Pará: Panorama. 2019a.

22. IBGE. Instituto Brasileiro de Geografia e Estatística. Belém. Panorama da Cidade de Belém. $2019 \mathrm{~b}$.

23. IBGE. Instituto Brasileiro de Geografia e Estatística. Ananindeua. Ananindeua: Panorama. 2019c.

24. IBGE. Instituto Brasileiro de Geografia e Estatística. Diretoria de Pesquisas, Coordenação de Trabalho e Rendimento. Pesquisa Nacional por Amostra de Domicílios Contínua: Rendimento nominal mensal domiciliar per capita. 2019d.

25. IPEA. Instituto de Pesquisa Econômica Aplicada. Radar IDHM. 2016, p.10-11.

26. ITÁLIA. Ministério da Saúde. Departamento de Proteção Civil. COVID-19-Situação na Itália (portal). 2020.

27. LU R, et al. Genomic characteris ation and epidemiology of 2019 novel coronavirus: implications for virus origins and receptor binding. The Lancet 2020, 395, 565-574.

28. NASSIRI R. Perspective on Wuhan Viral Pneumonia. Adv in Pub Health, Com and Trop Med: APCTM-106.

29. NORONHA KVMS, et al. Pandemia por COVID-19 no Brasil: análise da demanda e da oferta de leitos hospitalares e equipamentos de ventilação assistida segundo diferentes cenários. Cadernos de Saúde Pública. 2020; 36, 6: e00115320.

30. PEIRIS JSM, et al. Clinical progression and viral load in a community outbreak or coronavirus-associated SARS pneumonia: a prospective study. The Lancet. 2003; 361: 1767-1772.

31. SESPA. Secretária de Saúde Pública do Estado do Pará. Coronavírus no Pará (portal). 2020.

32. TIKELLIS C, THOMAS MC. Angiotensin-converting enzyme 2 (ECA2) is a key modulator of the renin angiotensin system in health and disease. Int J Pept. 2012; 2012: 256294.

33. WANG C, et al. A novel coronavirus outbreak of global health concern. The Lancet, 2020; 395: 470-473.

34. WHO. Word Health Organization. Report of the WHO-China Joint Mission on Coronavirus Disease 2019 (COVID-19). China: Word Health Organization - The Joint Mission. 2020.

35. WU Z, MCGOOGAN JM. Characteristics of and important lessons from the coronavirus disease 2019 outbreak in China: summary of a report of 72314 cases from the Chinese Center for Disease Control and Prevention. JAMA, 2020; 323(13): 1239-1242.

36. ZAKI AM, et al. Isolation of a novel coronavirus from a man with pneumonia in Saudi Arabia. N. Engl. J. Med. 2012; 367: 1814-1820.

37. ZHANG H, et al. Angiotensin-converting enzyme 2 (ECA2) as a SARS-CoV02 receptor: molecular mechanisms and potential therapeutic target. IntensiveCare Med. 2020; 46(4): 586-90.

38. ZHAO Y, et al. Single-cell RNA expression profiling of ECA2, the putative receptor of Wuhan 2019-nCov. bioRxiv. 2020.

39. ZHOU D, et al. Emerging understanding of etiology and epidemiology of the novel coronavirus (COVID-19) infection in Wuhan, China. Preprints 2020; 2020020283.

40. ZHOU P, et al. A pneumonia outbreak associated with a new coronavirus of probable bat origin. Nature, 2020b; 579: $270-273$. 